\title{
ECOLOGICAL AND SAMPLING CONSTRAINTS ON DEFINING LANDSCAPE FIRE SEVERITY
}

\author{
Carl H. Key \\ U.S. Geological Survey, Northern Rocky Mountain Science Center, \\ Glacier Field Station, West Glacier, Montana 59936, USA \\ carl_key@usgs.gov
}

\begin{abstract}
Ecological definition and detection of fire severity are influenced by factors of spatial resolution and timing. Resolution determines the aggregation of effects within a sampling unit or pixel (alpha variation), hence limiting the discernible ecological responses, and controlling the spatial patchiness of responses distributed throughout a burn (beta variation). As resolution decreases, alpha variation increases, extracting beta variation and complexity from the spatial model of the whole burn. Seasonal timing impacts the quality of radiometric data in terms of transmittance, sun angle, and potential contrast between responses within burns. Detection sensitivity can degrade toward the end of many fire seasons when low sun angles, vegetation senescence, incomplete burning, hazy conditions, or snow are common. Thus, a need exists to supersede many rapid response applications when remote sensing conditions improve. Lag timing, or time since fire, notably shapes the ecological character of severity through first-order effects that only emerge with time after fire, including delayed survivorship and mortality. Survivorship diminishes the detected magnitude of severity, as burned vegetation remains viable and resprouts, though at first it may appear completely charred or consumed above ground. Conversely, delayed mortality increases the severity estimate when apparently healthy vegetation is in fact damaged by heat to the extent that it dies over time. Both responses depend on fire behavior and various species-specific adaptations to fire that are unique to the pre-fire composition of each burned area. Both responses can lead initially to either over- or underestimating severity. Based on such implications, three sampling intervals for short-term burn severity are identified; rapid, initial, and extended assessment, sampled within about two weeks, two months, and depending on the ecotype, from three months to one year after fire, respectively. Spatial and temporal conditions of sampling strategies constrain data quality and ecological information obtained about fire severity. Though commonly overlooked, such considerations determine the objectives and hypotheses that are appropriate for each application, and are especially important when building comparative studies or long-term reference databases on fire severity.
\end{abstract}

Keywords: fire, burn, severity, fire effects, differenced Normalized Burn Ratio, dNBR, change detection, Landsat TM/ETM+

Citation: Key, C.H. 2006. Ecological and sampling constraints on defining landscape fire severity. Fire Ecology: 2(2): 34-59. 


\section{INTRODUCTION}

This paper concerns basic spatial and temporal factors that generally affect detection and definition of fire severity in a landscape context. Such factors result from the ecological conditions and dynamics that arise following fire, which largely determine the limitations and appropriate uses of derived information. Since remote sensing is a primary means to collect information across large burned areas, a focus is on how factors influence those results and the ecological conclusions drawn from them. The discussion is intended to be conceptual and apply generally across a broad spectrum of methodologies, recognizing that some approaches have unique properties or limitations that go beyond these considerations.

Burn assessments have a basic goal to gather reliable site-specific information over at least significant portions of impacted areas. Constraints on such efforts depend upon objectives, which can vary from quite general and simple to very specific and complex (Table 1). Often coincident with information specificity is increasing difficulty, cost, effort and modeled inference that can be accompanied by decreasing reliability or coverage. Thus, the acceptability of an approach depends on the intended content, quality and detail of desired information.

There are many factors that influence results, partitioned into two general groups; those physically based in the measurement systems or sensors used, and those closely related to fire ecology and ensuing responses. Many are important to non-fire-related applications as well, but particularly for fire effects and no matter what remote sensing technique is used, there are perhaps four conditions of the methodology that can influence and limit the definition of severity (Table 2).

A common challenge is to employ standard protocols to ensure comparable results from area to area and over time. That depends in large part on understanding the sensitivity of a method to the environmental conditions that influence fire effects and severity detection, which are not always straightforward. When factors in Table 2 differ between study cases, observed differences actually may be due to such factors and not to real fire effects. This paper attempts to demonstrate the influence of several important factors in Table 2, and identify relationships to ecological definitions of severity. An objective is to explore those variables and derived types of information commonly integrated into burn severity studies.

Table 1. A numeric, relative ranking of difficulty in determining different types information used in fire research and management at three levels of detail. Complexity and uncertainty in measures also tend to follow the numeric ranking

\begin{tabular}{l|c|c|c}
\hline \multirow{2}{*}{ Information Content or Specificity } & \multicolumn{3}{|c}{ Level of Detail } \\
\cline { 2 - 4 } & Low & Medium & High \\
\hline Burn Perimeter & 1 & 2 & 3 \\
\hline Area burned and not burned within perimeter & 2 & 3 & 4 \\
\hline Nominal burn categories, e.g. crown burn & 3 & 4 & 5 \\
\hline A continuous scale of severity magnitude & 4 & 5 & 6 \\
\hline Specific first-order effects, e.g. duff consumption & 5 & 6 & 7 \\
\hline Second-order effects and recovery, e.g. erosion & 6 & 7 & 8 \\
\hline
\end{tabular}


Table 2. Selected factors affecting quantification of fire severity and recovery are grouped into four conditions of the methodology.

\begin{tabular}{l|l|l}
\hline & \multicolumn{2}{|l}{ Factors Relevant to Modeling Fire Severity } \\
\hline Conditions & General Factors & Fire Specific \\
\hline Spatial & resolution & aggregation of effects \\
\hline Temporal & autocorrelation & patch size, contagion \\
\hline & site phenology & fire completion \\
\hline & moisture content & time since fire \\
\hline Radiometric & sun angle, snow & fire seasonality \\
\hline & sampling interval & \\
\hline & transmittance & smoke \\
\hline Geographic & available bandwidths & range of burn variation \\
\hline & reflectance & specific bandwidth response \\
\hline & geo-registration & ecotype properties \\
\hline & topography & elevation gradients \\
\hline
\end{tabular}

\section{BACKGROUND}

\section{A Conceptual Model of Severity and Recovery}

In this paper, the terms burn severity and fire severity are used interchangeably to refer to conditions that result directly from active fire, recognizing that distinctions between the two have been made (Agee 1993, DeBano et al. 1998, McPherson et al. 1990, Romme 1980). One context for discussion is that fire severity and recovery measure change from pre-fire and near-term post-fire conditions, respectively. Figure 1 displays a hypothetical response in one variable, which constitutes an individual fire effect. In nature, potentially a large number of variables are affected by fire, with unique dynamics that likely differ from one to the other but continue to track magnitudes of fire-caused change over time.

A second context is that responses are trends of individual ecological components. Some are more sensitive, while others are more resistant to fire, even to the point of being enhanced by fire. Thus, particularly in landscape studies, it is useful to consider that severity and recovery, though possibly represented by just one effect, actually encompass all the responses within some defined area to gauge the overall condition and summarize fire's ecological impact on the site. This is appropriate because: 1) many fire effects are very difficult to measure individually over large areas; 2) effects that can be monitored individually stand alone for specific objectives without the need for an overall gauge of severity; 3 ) just one or two individual effects may not represent the ecological condition of the area as a whole; and 4) though fire can affect components of the community differently, there is value in knowing the comprehensive ecological impact.

In Figure 1, the degree of change representing severity or recovery is a continuum against time. First-order effects are considered to be ecological consequences to components or conditions that existed before fire. The interval for sampling firstorder effects is relatively short following fire, as many effects fade and become altered by ensuing biophysical processes. Some form of this short-term severity is most commonly incorporated into the meaning of burn 


\section{Fire Response As A Measure Of Ecological Change} One Variable from One Fire Over a Site

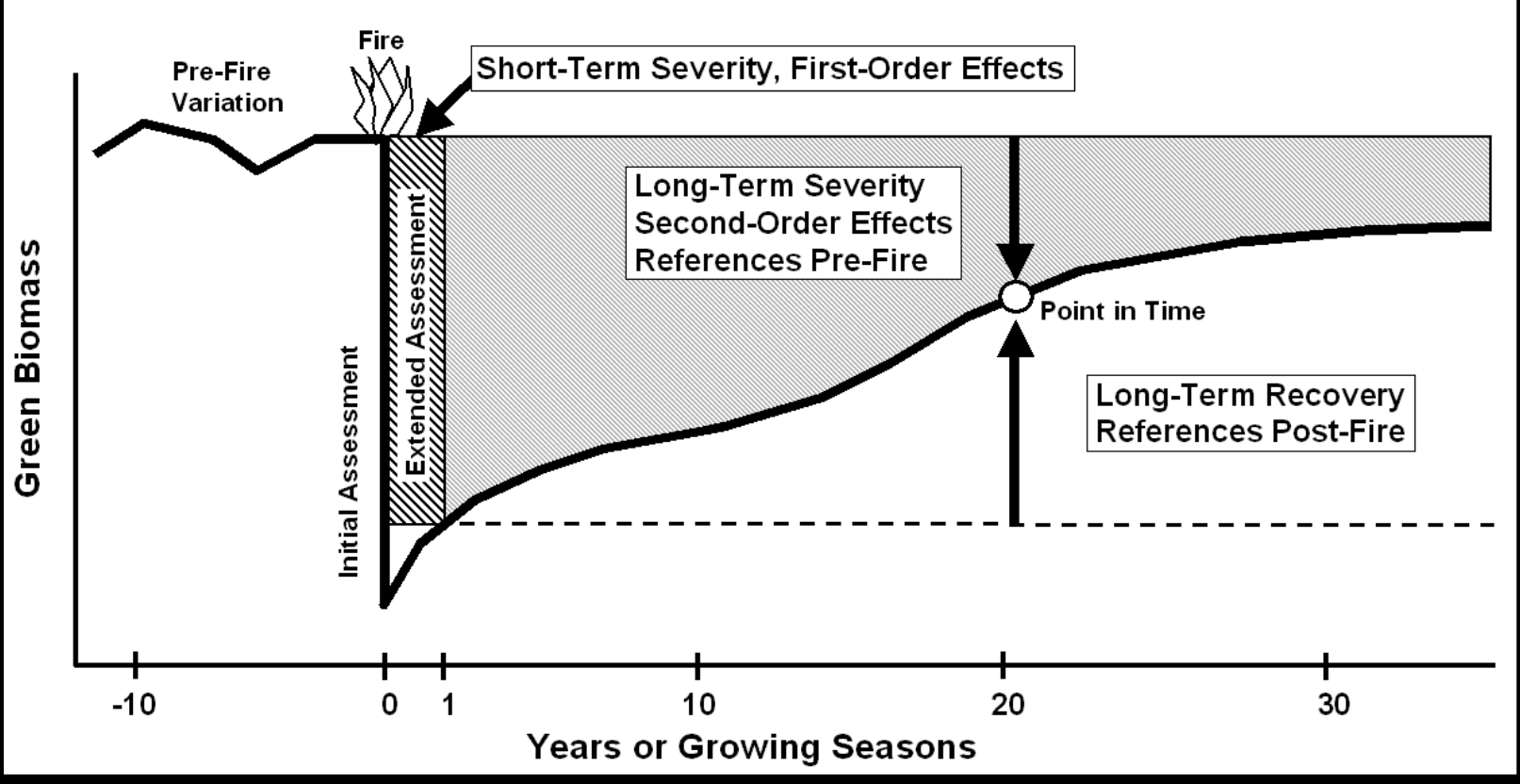

Figure 1. A conceptual model of burn severity and recovery that is dynamic over time.

severity, although there are longer-term implications. In particular, short-term severity initiates an interval of recovery by setting the reference conditions from which recovery is measured.

Many processes follow that control recovery, encompassing all biophysical elements and conditions arising on site. The implication is that recovery can differ between two essentially identical sites experiencing the same short-term severity, depending future conditions. Moreover, between compositionally different sites, recovery intervals can be very long or relatively short, depending on species adaptations to fire and interactions with climate, sil type and other factors, like seed sources (Grau and Veblen 2000, Abrahamson 1984, Huddle and Pallardy 1999).

At any point during recovery, its complement can be viewed as long-term severity, which continues to gauge the status of the burned area in relation to the pre-fire state. In addition, some elements during that period can be viewed as second-order effects and constituents of long-term severity (DiazDelgado et al. 2002). They include processes like erosion or disease that develop indirectly after fire and also potentially alter the trajectory of recovery.

The model suggests spatial and temporal dynamics to the definition of severity. It implies that the detected character of severity, as well as the potential performance of remote sensing, also varies along the continuum. Those issues seem to be at the core of apparent discrepancies between some studies, and sources of incompatibility when comparing results or defining severity. It is important, therefore, to be able to recognize and identify the spatial and temporal contexts inherent in specific measures of severity. The discussion below attempts to expand on key factors related particularly to fire disturbance over landscapes as viewed at moderate resolutions. 


\section{A Complementary Remote Sensing Index of Severity}

Only one index of severity is used throughout the paper, the differenced normalized burn ratio, delta-NBR or dNBR (Key and Benson 2006). While some have reported mixed results using dNBR in certain cases, it is not the purpose of this paper to evaluate the index per say. Rather, the intent is to focus on outside factors, independent of the remote sensing algorithm, which can affect the information received about burn severity. In addition, there exists a rich variety of other techniques for mapping burned areas, many of which predate or parallel the development of dNBR, such as Principal Components Analysis, the Multitemporal Kauth-Thomas protocol, spectral mixture analysis, and other classification techniques (Milne 1986; Patterson and Yool 1998; Rogan and Franklin 2001; Rogan and Yool 2001; Rogan et al. 2002; Sa et al. 2003; Hudak and Brockett 2004; Chuvieco et al. 2006). These have been shown to be useful in particular applications, and to model burn severity under alternative ecological definitions, including individual effects like tree mortality or burn categories like understory burn (Turner et al. 1994; Lentile et al. 2006). The dNBR is used in this paper, chiefly to have a common reference for comparison, and because it is relatively simple to produce and understand directly as a gradient of change. Moreover, the dNBR is appropriate in this context because, as a magnitude difference using bandwidths responsive to burning, it hypothetically fits the conceptual model of severity representing a magnitude of fire-caused ecological change.

López García and Caselles (1991) first demonstrated the efficacy of a normalized Band 4 - Band 7 difference to identify areas burned in Spain in 1984. They compared TM bandwidth reflectance within a burn to reflectance from a reference area outside the burn using single-date post-fire acquisitions.
They verified this "vegetation index" for mapping burnt area, and considered it a good parameter to gauge regeneration, although they did not suggest differencing the index, or discuss potential application for mapping burn severity. Unfortunately, their results did not receive much attention in the literature until about a decade later, for example, the absence from White et al. (1996) and GarcíaHaro et al. (2001). White et al. (1996) settled on classification of burn severity levels using only post-fire Band 7 reflectance, as the simplest and most useful approach tested for mapping severity on a 1988 burn. In the process, the study demonstrated individual bandwidth responses to burning, but in this case, the same area was compared from before to after fire using multi-temporal TM datasets. The post-fire NDVI and temporal change in NDVI were also evaluated.

Following White et al., this author then re-tested individual bandwidth responses on two northwest Montana fires that burned in 1994, using the same pixel locations in preand post-fire TM datasets. The results of all three investigations were quite similar regarding TM bandwidth response to burning within generally forested cover types. In essence, all found that Band 4 reflectance decreased the most of all bands, while Band 7 increased the most and had the greatest variation when comparing unburned to burned pixels. These responses were linked to the physical properties of reflectance in Band 4 shown to increase with increasing green vegetation cover and vigor, and the opposite response in Band 7, which decreases with vegetation cover and moisture content, but increases with greater cover of soil, ash or carbon (Knipling 1970; Tucker 1980; Ahern et al. 1991; Cibula et al. 1992; van Wagtendonk et al. 2004). The high Band 4 reflectance in spectra of vegetation is slightly reduced when vegetation is scorched, and dramatically reduced when vegetation is replaced by soil, ash and carbon (Kokaly et al. in press). Conversely, the very low Band 7 
reflectance over spectra of green vegetation is about equal to Band 4 when vegetation is scorched, but very high when vegetation is burned to ash, carbon and soil (Kokaly et al. in press). Band 5 has been shown to have similar absorption and reflective trends as Band 7, and has been used to gauge vegetation damage and moisture content (Vogelmann and Rock 1988; Collins and Woodcock 1994; Hunt and Rock 1989). However, the three studies agreed that the empirical measures for Band 5 response to burning, though similar to Band 7, were not as great and contained less variation than Band 7. Band 5 typically has reflectance levels intermediate between Bands 4 and 7 in the spectra of vegetation and ash/char areas (Kokaly et al. in press). Thus, the response of Band 4 relative to Band 5 was observed to be less extreme than the response of Band 4 relative to Band 7.

Without knowledge of López García and Caselles (1991) at the time, this author independently formulated and named the NBR in 1996, which turned out to be the same Band 4 - Band 7 normalized difference proposed earlier by López García and Caselles. The only distinction was the sampling strategy used to elucidate the index; one study referenced an area outside a burn in single-date imagery, while the other used the same set of within-burn pixels compared between datasets before and after fire. Once bandwidth sensitivity to fire effects were identified and encapsulated by NBR, however, the pre- to post-fire difference in NBR (dNBR) was examined in 1996 as an index of severity (Key and Benson 1999, 2002). One advantage of dNBR over the postfire NBR alone was it tended to isolate the burn from unburned surroundings (where the difference is near zero), while the NBR alone retained values that occurred naturally in both burned and unburned areas. Moreover, the dNBR provided a continuous scale of difference that could be related to a magnitude of ecological change, which in turn offered a conceptual model for burn severity, and a testable hypothesis, i.e. the greater the detected change by fire, the higher the severity. This enabled analysis with continuous environmental variables, and an alternative to more traditional categories of severity. The approach was fully documented in the 2002 Internet version of FIREMON (Lutes et al. 2006) within the chapter on landscape assessment.

Subsequently, dNBR has undergone extensive testing and use outside of northwest Montana, and has been found to be useful, considering simple algorithms derived from available Landsat bandwidths. Since 2001, it has been used nationally to map fires for the National Park Service (USGS EROS 2006). Follow-up investigations led to implementation of the dNBR when feasible to support Burned Area Emergency Response (BAER) teams (Gmelin and Brewer 2002; Orlemann et al. 2002; Bobbe et al. 2001). Recently, the Wildland Fire Leadership Council (WFLC) adopted Monitoring Trends in Burn Severity (MTBS), which relies on Landsat satellite imagery and the dNBR as a strategy to assess environmental impacts of large wildland fires and identify trends in burn severity across the U.S. A national evaluation for operational burn mapping in the U.S. involved over 2500 plots on 80 fires, and supported MTBS development (Zhu et al. 2006). In addition, several studies have been based on relatively few observations or only one to a few burns (Cocke et al. 2005; van Wagtendonk et al. 2004, Chuvieco et al. 2006; Finney et al. 2005; Miller and Yool 2002; Rogan and Franklin 2001; Lieberman and Rogan 2002; Brewer et al. 2005; Kokaly et al. in press). Others have been more regional in scope or spanned more than one fire season (Sorbel and Allen 2005; Bigler et al. 2005; Roy et al. 2006; Thode 2005; Miller and Thode in press; Hudak et al. 2004; Epting and Verbyla 2005). 


\section{METHODS}

Ecological and systematic factors affecting burn severity and its detection are illustrated using a combination of multispectral false color composites (FCC), band ratio differences, and frequency distributions of detected change magnitude within burns. The FCC images represent Landsat bands $7,4,3$ in red-green-blue (RGB), respectively. Cases are from an archive of burn assessments developed by the author since 1996, using 30-meter Landsat TM/ETM+ datasets that were geometrically terrain corrected and normalized to band reflectance. Burn perimeters were produced from onscreen digitizing, referencing pre- and postfire Landsat and dNBR imagery.

The dNBR (Key and Benson 2006) is based on the normalized burn ratio (NBR), which is the Landsat TM/ETM+ band 4 to band 7 reflectance difference, divided by the sum of the two reflectances $\left(N B R=R_{4}-R_{7} /\right.$ $\left.R_{4}+R_{7}\right)$. The dNBR is the pre-fire to postfire difference in the NBR $\left(d N B R=N B R_{P R E}-\right.$ $\left.N B R_{P O S T}\right)$. The NBR varies between -1.0 and +1.0 , where burned areas take on distinctly negative values, at times lower in magnitude than non-vegetated and unburned background surfaces, such as soil and rock. Vegetated areas are highly positive, generally increasing in value with the amount and vigor of green vegetation. Thus, NBR alone is potentially sensitive to reflectance characteristics that result from burning, and can contribute to classification of fire effects based on surface materials (Hudak et al. 2004; Kokaly et al. in press). The dNBR can vary between -2.0 and +2.0. Typical burned areas are either distinctly positive or negative. Unchanged, or theoretically unburned areas retain values near zero. The dNBR is scaled by 1000 in this paper for the ease of interpreting and processing integer values. For comparability, all dNBR images have a linear grayscale between -800 (black) and +1100 (white).
Unburned areas are compared to burned areas using obvious visual differences, and statistical properties of the two populations of pixels extracted from the imagery. Unburned statistics and frequency histograms are based on samples drawn from outside burn perimeters $(\mathrm{N}>10,000$ pixels each case), avoiding areas that may have changed due to other anthropogenic or natural causes, such as logging or snow cover. Within-burn populations of pixels are extracted using the burn perimeters to produce the burned-area statistics and histograms.

\section{RESULTS AND DISCUSSION}

\section{Spatial Constraints - Alpha Severity (Intra-Site Variation)}

Spatial factors affect information about burns through interactions between resolution and the ecological responses possible to detect (Chen 1999, Liang 2000). This includes the variation that occurs within the minimum sampling unit, as well as variation between units, i.e. throughout an entire burn. These sources are the intra- and inter-site variation in severity, respectively, introduced here as alpha and beta variation, or alpha and beta severity. The terms can be considered analogous to concepts of within-habitat and between-habitat diversity, or alpha and beta diversity as proposed by Macarthur (1965).

As illustrated in Figure 2, the general trend of detectable alpha variation lessens with decreasing resolution. At left, the field view reveals detail that can be measured throughout a 30x30 m site. Here, effects such as char height on each tree, and survivorship of individual understory species can be differentiated and used either individually or collectively to establish the burn severity. At 0.3 to $1.0 \mathrm{~m}$ resolution (center), the 30 -meter site retains some alpha variation, like scorch to individual tree crowns, but the number of discernable severity indicators is reduced. 


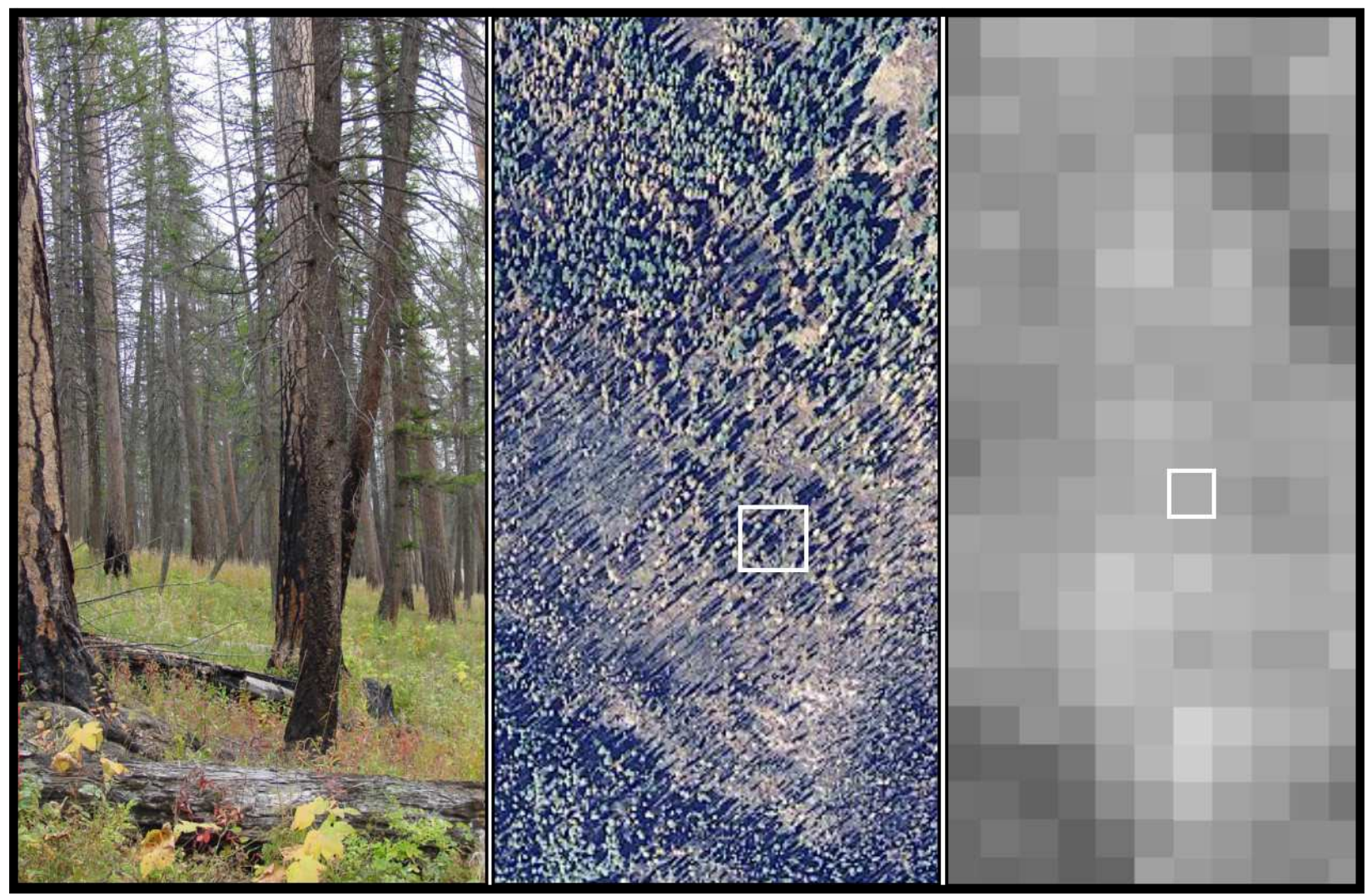

Figure 2. Stepwise aggregation of fire effects occurs as spatial resolution decreases. From left to right, field photo taken about 1 year post-fire; color aerial photo 1 month post-fire; dNBR image using data from 1 month post-fire. White squares, roughly 30x30 m, denote approximate location of the site shown at left.

General survivorship and consumption patterns in the understory still can be assessed separately from the overstory, but understory effects predominantly represent overall conditions rather than species-specific responses. The site, however, now appears in context with surroundings, which enables spatially uninterrupted assessment over broader areas and a measure of beta severity.

As resolution decreases to $30 \mathrm{~m}$ (right), components of the site are not detectable individually, being reduced to a single, synoptic value for the whole pixel. In ecological terms, all understory and overstory effects become spatially and compositionally integrated into an average condition for the whole area to represent the site severity. Data at this level records no alpha variation, except what may be established independently at higher resolutions. We know, for example, that site severity can be inherently complex when ecological effects are examined within $30 \mathrm{~m}$ field plots. Also, spectral mixture analysis can estimate proportional composition of 30-meter pixels, when material endmenbers are established previously at higher spatial and spectral resolutions (Ustin et al. 1993; Caetano et al. 1994; Rogan and Franklin 2001; Hudak et al. 2004).

A question arises then, concerning what burn attributes are captured by remote sensing at the 30-meter site level. If the quantity is a blend of individual effects as described, severity field measures should reflect the spatial extent and aggregation recorded by remote sensing. The Composite Burn Index (CBI) attempts such a rating, derived from an average of 4-5 rating factors per each of five potential strata in the ecological community 
(Key and Benson 2006). Where in turn, each factor reflects the average condition of a fire effect across the area of the plot. Ideally, once site severity is defined in such a manner, field measures and remote sensing values should match appropriately for content, and correlate effectively (Figure 3, left). In practice, it is often difficult to gauge the average condition of fire effects across a 30-meter site, and difficult to discern the change relative to prefire conditions, since pre-fire conditions are often radically altered by fire. However, if the field definition of severity does not match the remote sensing capability, then one can expect even more noise in the burn model, as remote sensing captures ground components unrelated to the desired definition being measured in the field.

Secondarily, site severity may be related back to individual effects, such as newly exposed mineral soil, but with varying degrees of reliability (Figure 3, right). A similar observation was made by Hudak et al. 2004 when attempting to relate individual effects to 30-meter derivations of severity. At very low or very high severity, such associations can be relatively certain. In middle ranges, where alpha variation in the plot can be high, individual effects are not expected to be uniform from site to site (Peterson and Stow 2003, Schimmel and Granstrom 1996). Fire intensity and ecological response can vary over the 30meter site, while each stratum and component may be affected differently. It follows that similar aggregate magnitudes of severity can result from different combinations of effects and burn pattern within the site. Moreover, some effects, such as litter consumption, reach maximum possible levels before maximum severity is reached, so they are not expected to show any relationship to severity above certain levels. Thus, ability to detect and model individual ecological effects, though partly limited by radiometric factors, is also spatially constrained by resolution and decreasing detectable alpha variation.

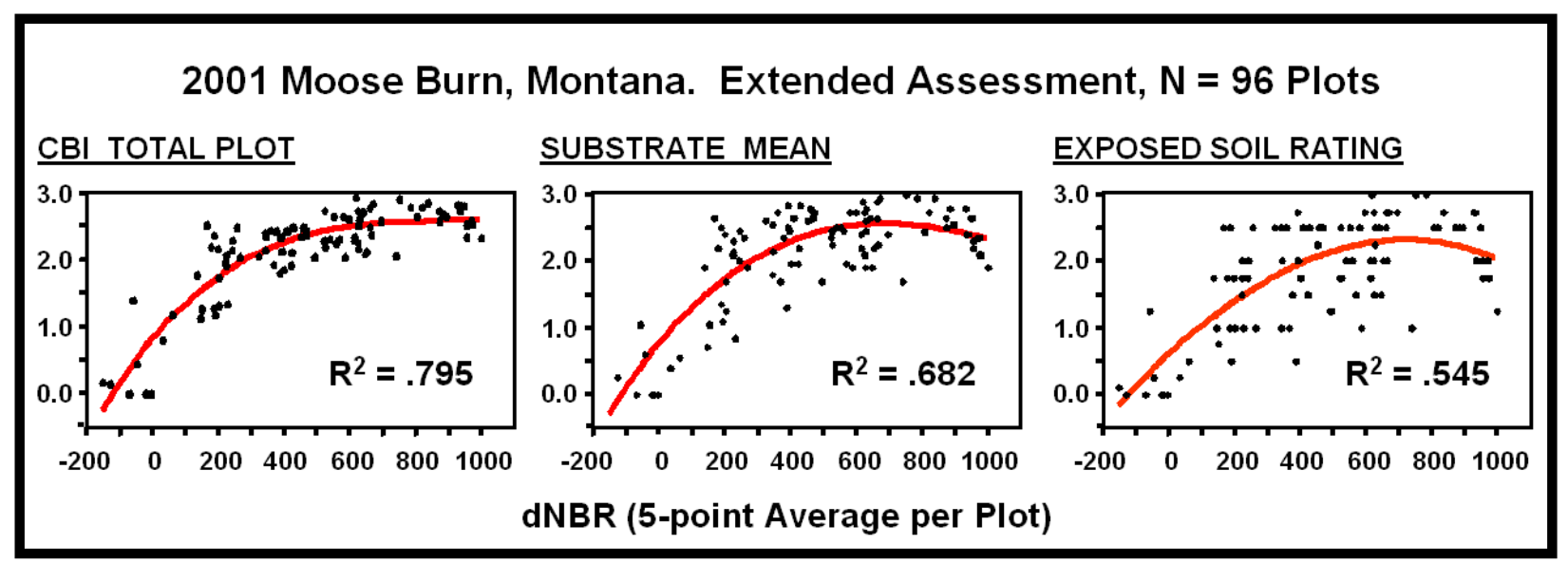

Figure 3. Graphs show relationships between CBI field measures of severity and the dNBR, i.e. the change detected by Landsat. Total plot scores average all rating factors over all 5 strata on the plot, the substrate mean is one of 5 strata integrated into the total plot score, and the exposed soil rating is one of 5 factors averaged into the substrate mean. General disaggregation of fire effects tends to lessen correlation to the 30-m dNBR (to the right), such that individual effects are less reliably predicted at 30-m than are other composite measures of site severity. 


\section{Spatial Constraints - Beta Severity (Inter-Site Variation)}

Beta variation impacts the ability to define ecologically important burn characteristics, such as edge, mosaic complexity (the variety and distribution of patches), and the overall range of responses (Slocum et al. 2003, Beaty and Taylor 2001, Weir et al. 2000, Chen 1999). Other affected attributes include the derived sizes of burns and the area of sub-units, e.g. distinct burn classes, watersheds or affected ecotypes (Nelson 2005, Soja et al. 2004). Figure 4 illustrates qualitative differences in beta severity that result from different sampling resolutions. At upper left, a color aerial photo taken soon after fire shows sharp boundaries for larger patches of crown fire, and degrees of crown scorch down to individual trees. Very small patches and much spatial complexity are evident in the burn mosaic.

For comparison, the other images in Figure 4 are subsets of a 30-meter dNBR, based on post-fire Landsat TM from about 10 months after fire. The grayscale corresponds to a linear gradient of change in NBR, with zero or no change being the medium gray lying mostly outside the burn. Higher positive and negative values are increasingly lighter and darker tones, respectively. Both represent degrees of departure from the neutral unburned condition, and relate to effects caused by fire when within the burn perimeter. Rising positive dNBR corresponds basically to increased scorch, char, ash or soil, and decreased green vegetation compared to pre-fire. The more negative the dNBR, the more plant growth is enhanced by fire over pre-fire conditions through nutrient and competition effects (McCarron and Knapp 2003). Strongly negative dNBR pixels are visible in Figure 4 as small dark patches of mostly herbaceous vegetation that burned on moist sites.

Compared to the aerial photo, decrease in beta variation is evident in the $30-\mathrm{m}$ dNBR (upper right). Minimum patch size increases, edges are less distinct, and thin linear features disappear, as alpha variation captured by individual pixels increases. General shape and distinction of larger patches, however, are preserved. The mosaic retains at least the range and distribution of beta severity depicted in the aerial photo, with roughly one-to-one correspondence between larger patches. At $30 \mathrm{~m}$, a pixel may overlap different burn conditions, but alpha variation is generally less than variation found between entirely dissimilar ecological communities or distinct burn patches. As a result, $30 \mathrm{~m}$ tends to suitably capture beta variation for wholeburn coverage and landscape perspectives on fire responses (lower left). Ecological inferences at this level are somewhat different than from the aerial photo, with a general trade off of detail for spatial coverage and aggregation of effects. In practice, $30-\mathrm{m}$ data is more efficient to use as a single contiguous dataset in whole-burn studies than higher resolutions, especially for burns exceeding ca. 3000 ha; while it remains suited for standlevel and watershed summaries.

As resolution decreases to $500 \mathrm{~m}$ and 1 $\mathrm{km}$, whole-burn heterogeneity incrementally declines as attributes of beta-severity get incorporated into the alpha variation of the larger grid cells (Figure 4 lower). Portions of multiple dissimilar patches become aggregated, small patches consolidate with surroundings, and very few patches remain intact. Few patches are represented distinctly by pure cells of severity or stand type. The averaging reduces the potential range of values, greatly decreases the contrast or edge between distinct patches, and impacts the ability to monitor small habitats, like meadows or wetlands. Thus, the within-cell ecological definition of severity is altered by broadened alpha variation. It encompasses between-stand characteristics and a broader diversity of burn conditions. 


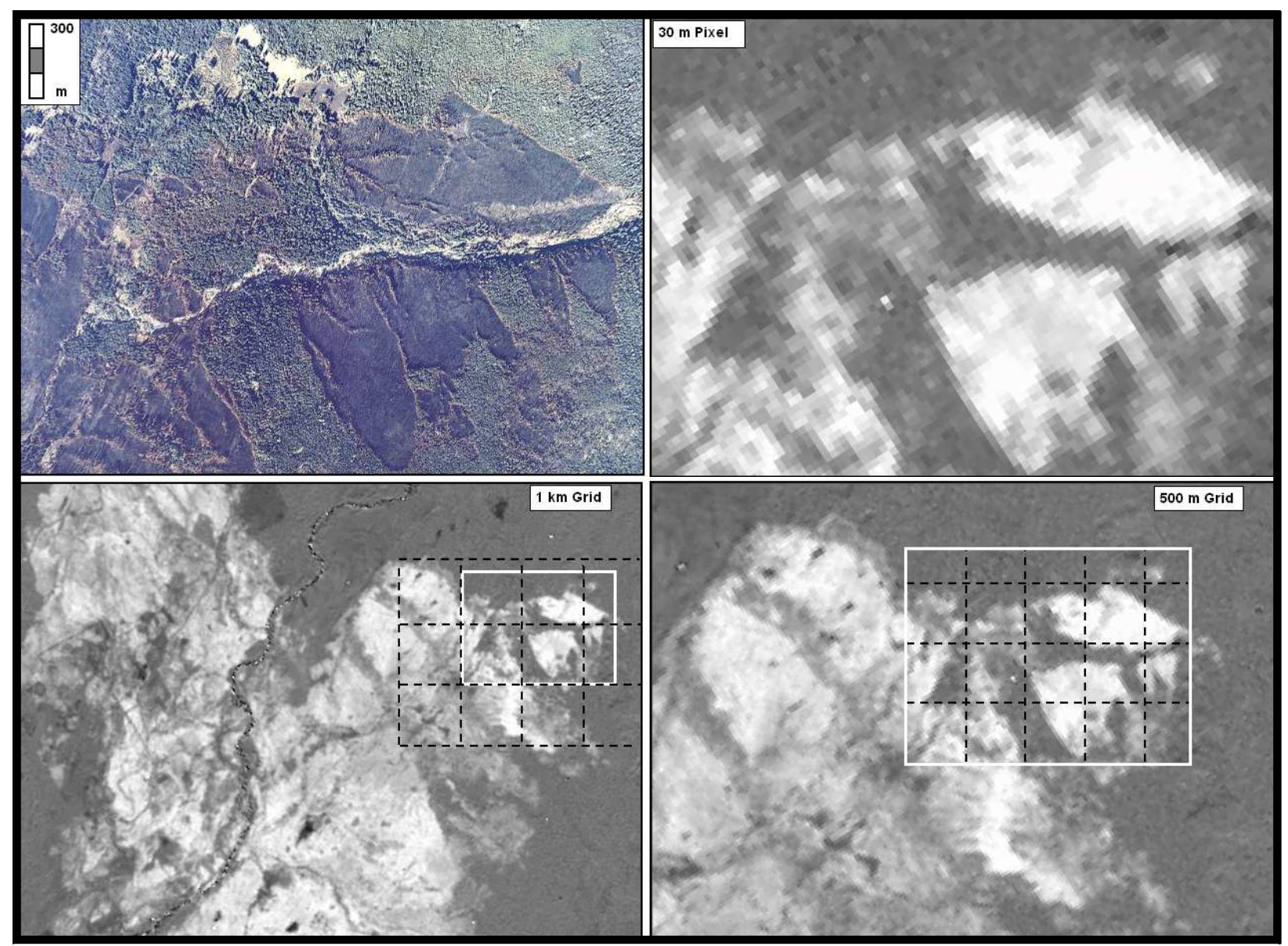

Figure 4. Burn pattern viewed at different scales (top left 0.3-1 m resolution; others $30 \mathrm{~m}$ ). Grids provide a reference to beta variation pooled into individual pixels at lower resolutions. Coverage is about one third of a 13,780 ha burn from 1988.

The influence of resolution is a function of fire-created patchiness, where in most ecotypes, natural spatial variation in fire behavior and effect is more fine scale than can be modeled at increments of 500 to 1000 $\mathrm{m}$ (Price 2003, Romme 1982, Soja et al. 2004). Nelson (2005), for example, indicates that burn sizes need to be much larger than 5,000 ha before 500-m MODIS data adequately estimates the area burned. The same may apply to effectively map and estimate the size of distinct patches within burns. Thus, the lower resolutions may be suitable for sub-continent to global scales, where cruder estimates would suffice for regional totals of all burns, but not to represent the beta variation within individual burns.

\section{Temporal Constraints - Seasonal Timing}

Temporal factors strongly influence the measure and detection of fire severity and recovery, including the time of year (seasonal timing) and time since fire (lag timing) for sampling. These influences result from the dynamic nature of fire responses, and from non-fire-induced biophysical conditions that normally vary throughout a year.

Seasonal timing relates to the time of year when sampling occurs. In remote sensing, timing can detract from fire assessment in many temperate regions when data acquisition closely follows the fire season, which is typically dry or during months distant from the summer solstice. Other factors aside, indices like dNBR in late 
season can show less contrast within the burn and less distinction between burned and unburned areas (Figure 5), when naturally senescent and dry unburned vegetation can mimic scorch or girdle associated with low fire impacts. Conversely, generally better contrast and a broader range of severity can be detected with dNBR when unburned vegetation is relatively green and productive. Unburned green vegetation contrasts greatly with burned vegetation, especially when effects include light scorching or mottled burn patterns. Snow is also a factor in mountains for both early- and late-season acquisitions. If fire spans a large elevation range, it may be necessary to process two post-fire datasets, in order to capture the best time for phenology and snow in low and high elevation areas, respectively.

A compounding influence of seasonality is the low sun angle that accompanies earlyand late-season acquisitions at middle to high latitudes (Miura et al. 2001). Generally, poor illumination and increased shadow, even on relatively flat terrain occupied by tall vegetation, decreases the definition of fire effects and sharpness of burn images (Figure 6 left). Low reflectance effectively degrades burned and unburned qualities, and very dark shadow effectively eliminates large areas from analysis (appearing speckled with high and low dNBR values). By contrast, images in Figure 6 right are much more distinct and enhanced by the better illumination near

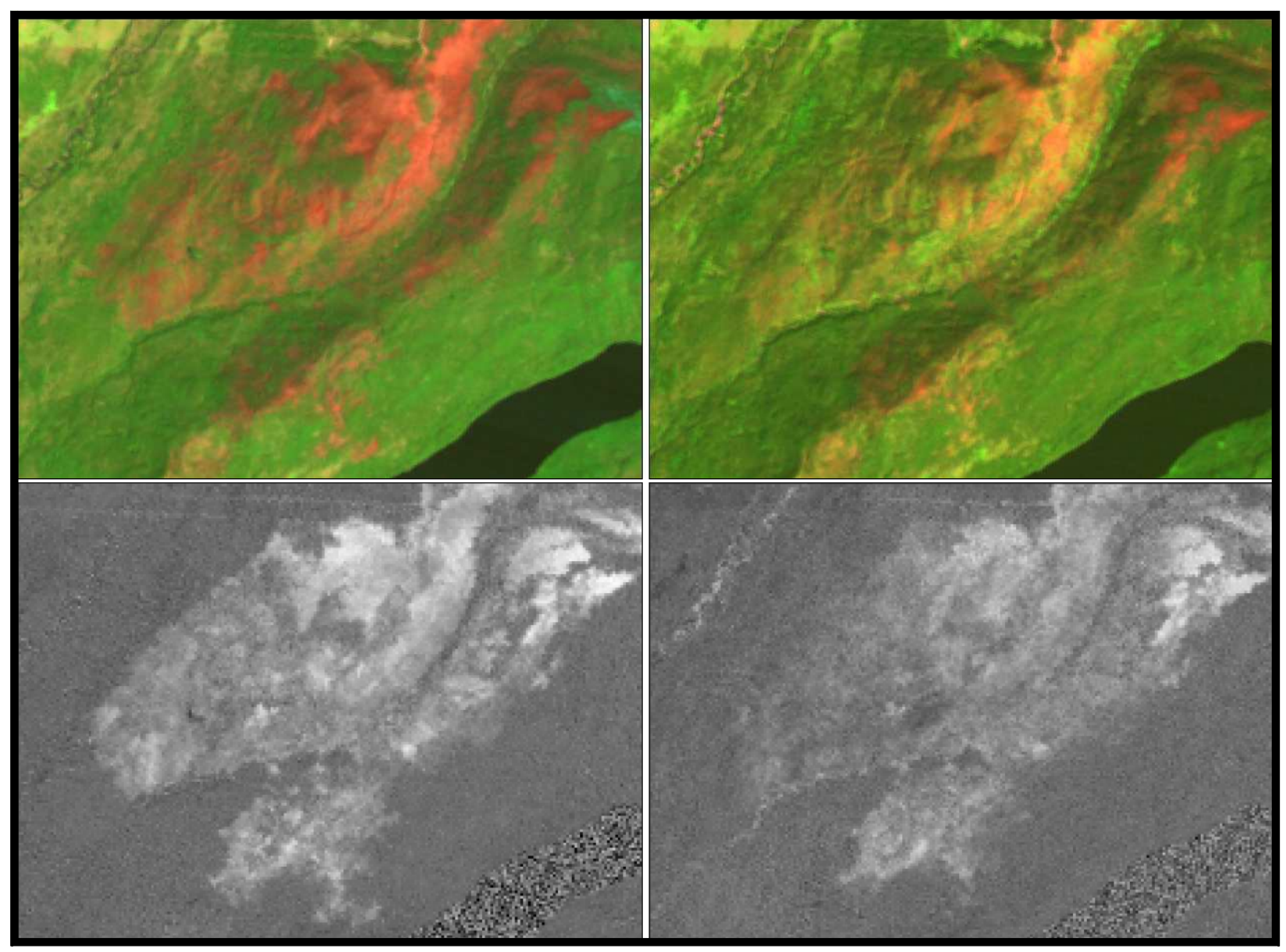

Figure 5. Top, post-fire Landsat TM band 7,4,3 RGB composites; bottom, derived dNBR. Images at left are during the growing season, 28 May 1995; and at right, from near-end of growth, 1 Sept. 1995. The fire occurred in August 1994. 
summer solstice, even on slopes facing away from the sun. A diagnostic characteristic is the narrower range and more uniform values of dNBR in unburned areas (lower right), which enhances burn distinction and detection of ecological changes.

Seasonal timing is most relevant to multitemporal analyses, or when several burns are compared using datasets from different times. To isolate change only due to fire, and to minimize affects from other processes, multitemporal datasets should represent similar environmental conditions outside the burn. In regions with predictable seasonality, images from near the same time of year may serve that purpose, but adjustments are frequently needed to account for inter-annual variability. When pre- and post-fire datasets are adequately paired for sun angle and phenology, unburned areas show little beta variation, and differenced-values are near zero with similar gray tone (Figure 6 lower right). A frequency distribution of unchanged pixels (used to test correspondence between scenes) tends to be normally distributed with a mean $\mathrm{dNBR}< \pm 20$ and standard deviation ca. $<50$, on a scale of -2000 to +2000 (Figure 8 left). These conditions can model unburned areas more correctly as being ecologically unchanged by fire.

If pre- and post-fire datasets are not suitably matched, results like Figure 7 are

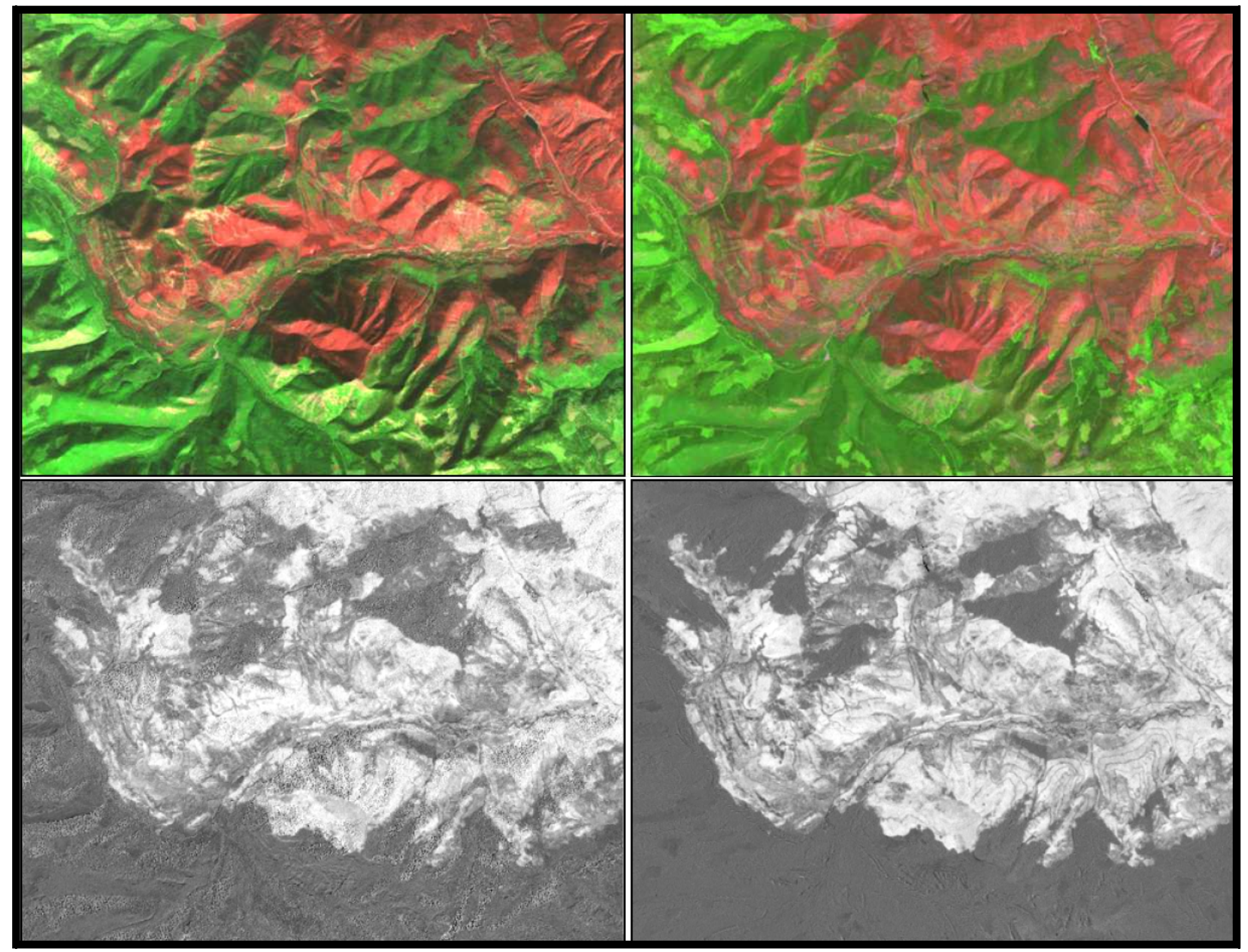

Figure 6. Images emphasizing the impact of sun angle (illumination) on severity assessment capability. Post-fire FCC top, corresponding dNBR bottom; 3 October 2001 left, 7 July 2002 right. 
diagnostic. The dNBR shows higher (lighter) values where pre-fire conditions, left, are evidently more productive and greener than the post-fire, center. (Oppositely, lower dNBR results when the post-fire state is greener.) However, the area is not burned; so detected change in NBR is not due to fire but rather to natural phenological difference between acquisitions. This result is undesirable as it lessens the distinction between burned and unburned, and creates false positives for fire effects when near or within burn perimeters. Severity levels of burned pixels are also biased. With mismatched scenes, large samples of dNBR unburned pixels may not be normally distributed, and tend to have means ca. $> \pm$ 20 , on a scale of -2000 to +2000 (Figure 8 center and right).

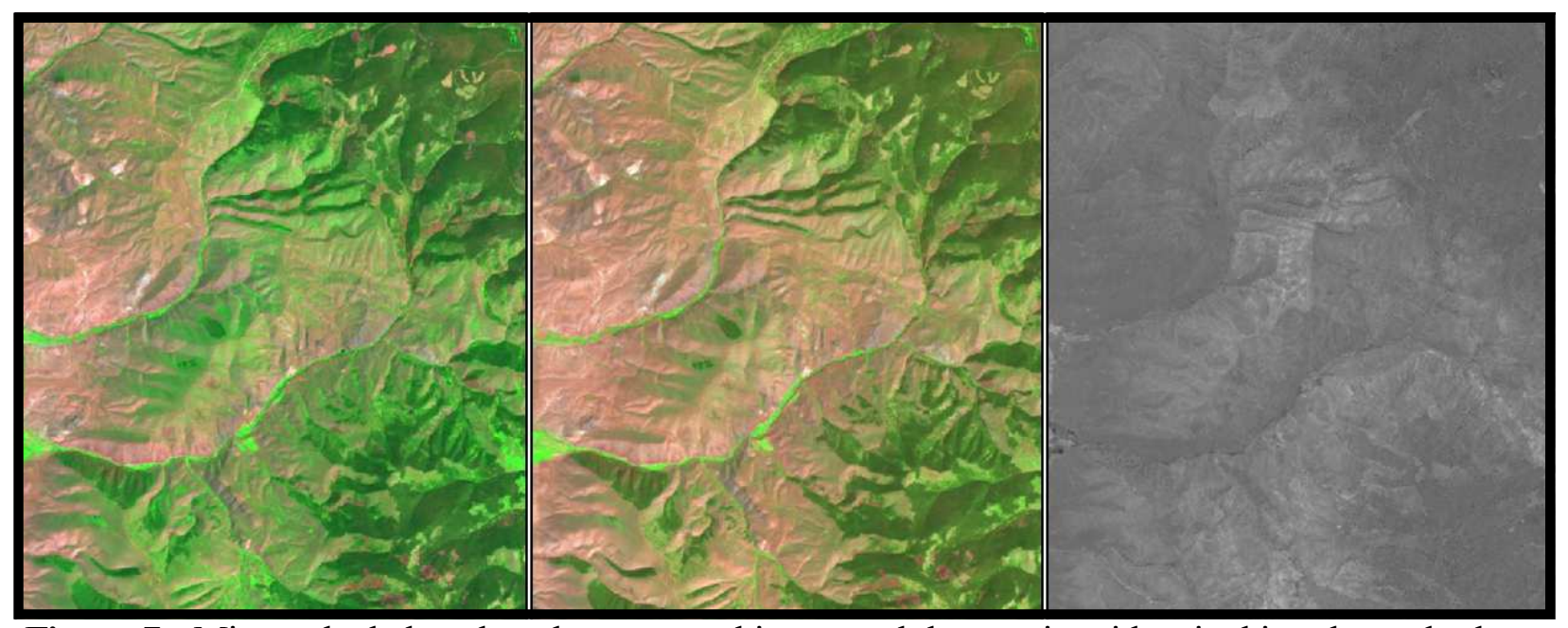

Figure 7. Mismatched phenology between multi-temporal datasets is evident in this unburned subset. The dNBR, right, was derived from Landsat TM 16 July 1998, left, and ETM+ 1 August 2001, center.

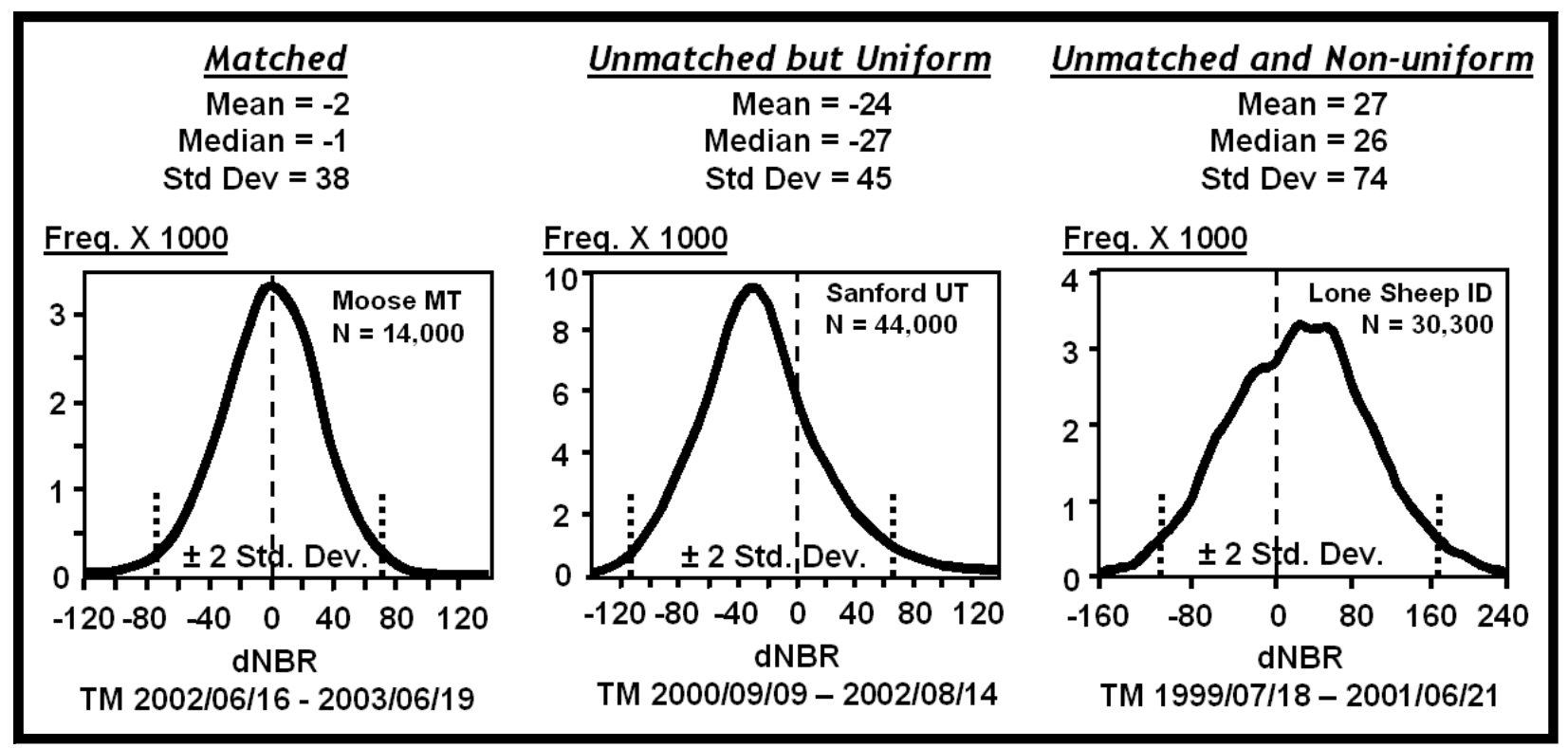

Figure 8. Statistics from populations of unburned pixels sampled from different dNBR datasets, where the pre- and post-fire scenes were (left to right) phenologically matched, phenologically unmatched but consistently so throughout the area of interest, and phenologically unmatched in spatially variable ways over the area of interest. 
Bias in the unchanged-pixel mean represents average phenological difference or possible atmospheric effects between acquisitions, when known causes of change (e.g. land use, fire, infestation, or snow) are avoided in sampling. If beta variation within unburned is spatially uniform (unlike Figure 7), the biased distribution is approximately normal with a standard deviation ca. $<50$ (Figure 8 center). In those cases, the unchanged-pixel statistics can be used to calibrate one dNBR to another, by subtracting the bias from the dNBR dataset. Then, the adjusted unburned distribution has a mean of zero to better represent no ecological change due to fire. Figure 8 center is a case where shifting the dNBR by about +25 points would be warranted, due to the normal distribution and relatively low standard deviation. This would tend to compensate for the ecological difference between scenes that was not related to fire, and make fire-caused change more directly comparable between the dNBR datasets.

Figure 7, however, depicts fairly high beta variation across the unburned dNBR, even though the paired dates are similar. Such temporal and spatial disparity in phenology is difficult to balance without properly matched scenes. Unburned dNBR may not be normally distributed, and the bias and standard deviation are typically larger than the previous examples (Figure 8 right). Because the ecological effect is spatially variable, general calibration by the unchanged bias may not be desirable. This scenario may be common in alpine or dry ecotypes, including herb and shrub communities that are moisture or snow limited (Grau and Veblen 2000). Growth can vary dramatically year-to-year depending on stochastic weather; so multitemporal scenes can be challenging to match. The distribution and density of green foliage, soil moisture and snow are key factors, not simply time of year. Obviously, datasets that are not phenologically matched have reduced application to burn analysis derived from multi-temporal ecological difference.

\section{Temporal Constraints - Lag Timing (Time Since Fire)}

Preceding post-fire assessment, information on fire progression and intensity may exist if fires were actively managed. Several incident teams may rotate in and out during the course of one fire, contributing several sets of fire data that may not be fully integrated after the fact. Many techniques may be used to map the going fire, including nighttime thermal infrared imaging and daytime aerial observation, so data may not be standardized overall. The information can be useful for post-fire assessment, but caution should be exercised if applied to research or long-term management as quality and content can be variable, while sufficient documentation of methods may be lacking.

The quality of incident-derived fire perimeters is variable, depending on methods and source data, but they may serve as starting points for post-fire assessment. Aside from general precision, several situations influence whether incident perimeters delineate the actual extent of burning. First, perimeters may outline the containment area out to defensible fire lines, while fire may not have actually reached some of those lines. Second, perimeters may be intentionally generalized and not closely follow very convoluted or complex fire boundaries. This may be done to better represent the area actually managed, or to legitimately justify management costs. Third, incident perimeters are only current up to the last observation, or until the incident teams demobilize, which can be before the actual end of burning, especially in remote areas or where societal values are no longer threatened. Finally, incident perimeters may be extended to include small spot smokes, e.g. from one log, that represented a potential fire hazard at the 
time, but never developed into a sizeable burn patch detectable at the resolution of post-fire sampling. Outlying spots may be retained for interest in fire behavior, or simply ignored if they are insignificant at the scale of assessment. In any case, adjustments to incident perimeters are usually warranted when the intent is to accurately record the outermost extent of burning using the most up-to-date information.

Post-fire assessments, on the other hand, are meant to determine the actual ecological impact of fire, building from and perhaps revising information collected at the time of active burning. In addition, they document the many fires that were not managed in the first place or have incomplete incident records. A key objective for many applications is to capture the spatial distribution of short-term severity. As shown in Figure 1, however, the ecological quantity and quality of severity is very much linked to the lag time when measurement occurs. Thus in practice, three sampling intervals are identified here as rapid, initial, and extended assessment. Each has slightly different information content and constraints on quality and function (Table 3 ).

Rapid assessment (RA) almost exclusively assists post-fire emergency response (USFS RSAC 2005), which applies to typically larger fires or fires affecting valued resources or human assets. RA is not done on many fires due to expense or lack of necessity, so the number of RA fires is a subset of all fires. Since time is critical, planning and initiation of ground work dictate that products be completed within about two weeks after significant burning, often before the fire is completely out (Figure 9). In most cases, RA adequately serves to locate larger areas of high severity that constitute treatment priorities. Remote sensing data are often limited within the timeframe, however, so over many incidents, circumstances compel using a variety of approaches to offset the chance of getting no data from a particular source, like Landsat. Moreover, timing often comes when seasonal factors constrain the content and delineation of burn severity and perimeters, as discussed above (Miura et al. 2001), and results may record partial effects or lingering smoke. Where burning is complete, effects are raw and may

Table 3. General characteristics of burn severity assessments and potential traits arising with lag time after fire. For information content, P signifies perimeter and S severity, "_" and "+" indicate general potential for information completeness. See text for explanation.

\begin{tabular}{l|l|l|l}
\hline Conditions & Rapid & Initial & Extended \\
\hline Time Since Burn & $<2$ weeks & $1-8$ weeks & $2-12$ months \\
\hline Burn Completion & Often burning & Most are complete & Complete \\
\hline Fire Coverage & Larger, by request & Most $>$ minimum size & All $>$ minimum size \\
\hline Data Availability & Limited & More & Most \\
\hline Data Source & Multiple & Single & Single \\
\hline Method & Variable & Single & Single \\
\hline Information Content & P-, S- & P, S- & P, S+ \\
\hline Delayed Mortality & Undetected & Slightly detected & Detected \\
\hline Survivorship & Undetected & Slightly detected & Detected \\
\hline Phenology & May be senescent & May be senescent & Green \\
\hline Transmittance & Variable & Likely better & Likely good \\
\hline Sun Angle, Snow & Variable & Variable & Best possible \\
\hline Potential Quality & Variable & Variable & Often good \\
\hline Uses and Term of Use & Limited & May be limited & Final reference \\
\hline
\end{tabular}




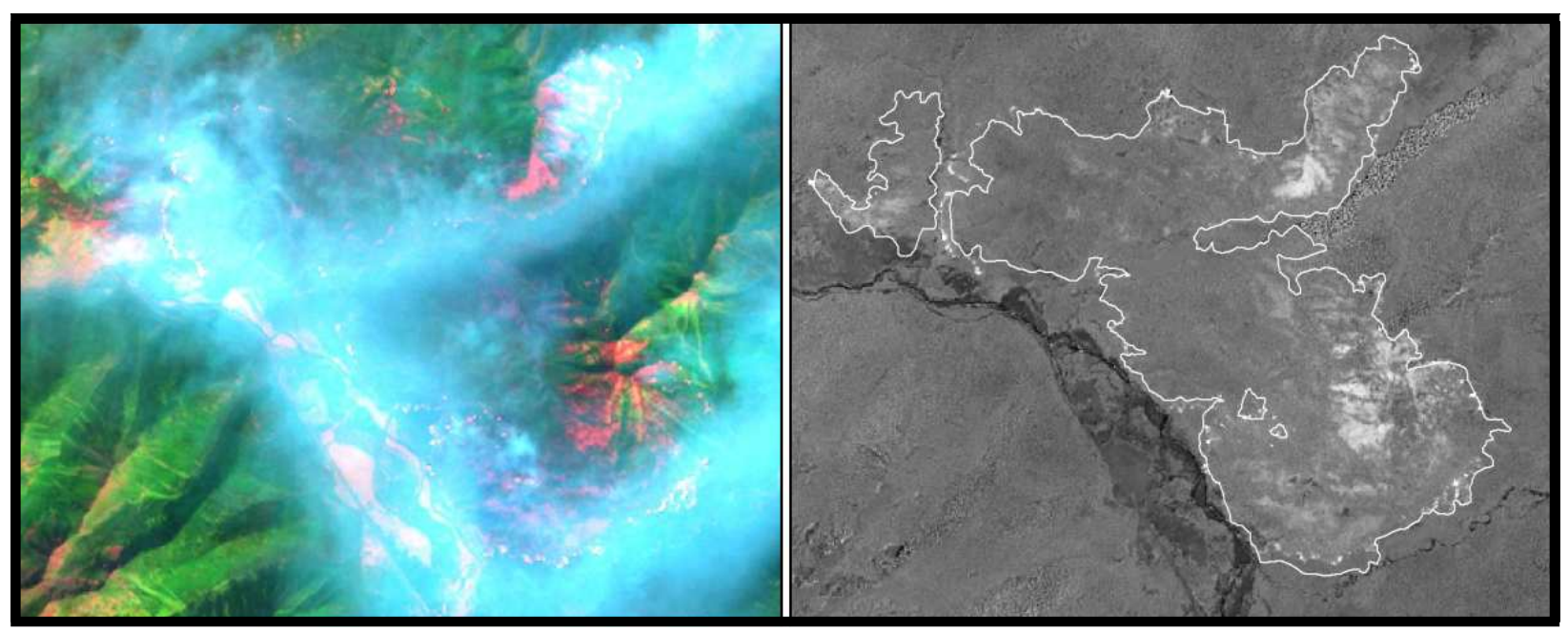

Figure 9. RA with burn perimeter, post-fire 7 September 2003. dNBR, right, penetrates smoke to provide some information useful to emergency response; bright spots of active burning occur near perimeter. Compare to Figure 10.

not include some indicators of severity, such as vegetation survivorship or delayed mortality (Bond and Midgley 2003, Abrahamson 1984, Fowler and Sieg 2004). Thus over all fires, RA is less standardized, which, though necessary for the intended purpose, diminishes its long-term utility. Also, for data quality and content concerns, the collective application of RA to research and long-term management is more limited. Yet, data from RA is often used in those contexts, while there is a need to supersede the RA with better, more complete and standardized information after the emergency response. Some RA can be done with highquality optimal data, but the variety of potential problems makes achieving consistently good results difficult.

Initial assessment (IA) is the first opportunity to get essentially complete ecological evaluation of a burn (Figure 10 left), initiated ideally when 1) burning has ended, and 2) quality data are available. Secondarily, the non-emergency situation enables use of standard comparable data from one remote sensing approach across all targeted burns. Usually all fires over some practical minimum size are candidates for IA with less restrictive coverage than RA. Flexibility exists to wait for high quality satellite acquisitions, and occasionally, opportunities to compare multiple acquisitions. If reliable data is acquired within about two weeks of fire, and emergency planning is still in progress, then IA and RA are essentially the same, distinguished only by the data standards of IA. However, the wait for fire completion and improved atmospheric conditions usually extends IA for up to two months beyond the period for RA. Despite the prolonged interval, suitable acquisitions still may not be available from the sensor. In addition, IA is subject to the same limitations as RA when it comes to sun angle and phenology, with possible slight improvement in detecting survivorship or delayed mortality (Kauffman and Martin 1990). On the other hand, perimeters and severity may be more representative of the final state of the burn than RA.

Extended assessment (EA) occurs during the first growing season after fire (Figure 10 right). It captures first-order effects that include delayed survivorship and mortality of vegetation present before fire. Survivorship is 


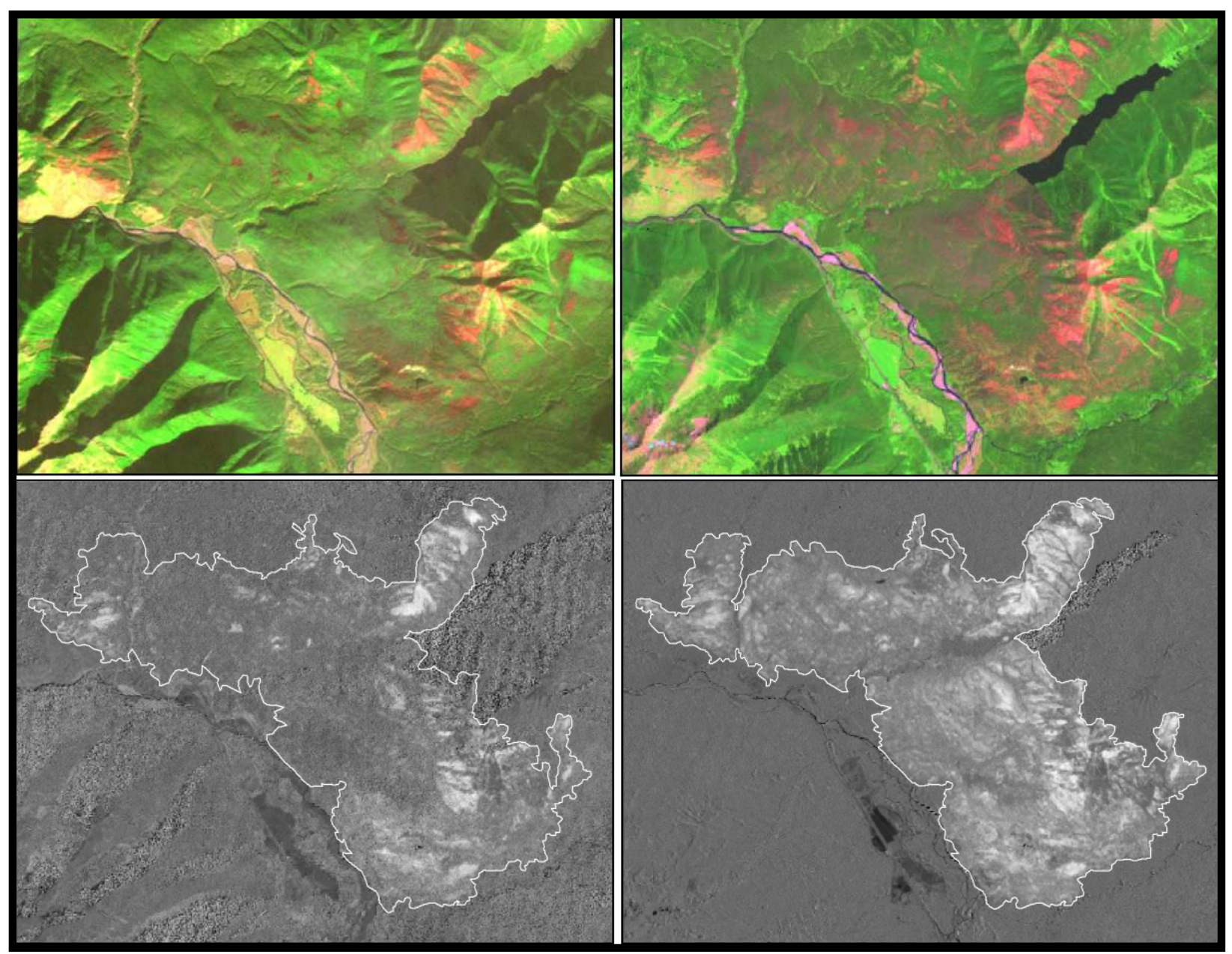

Figure 10. Different perimeters and levels of change are detected in IA (left) and EA (right). Post fire scenes were 25 Oct. 2003 and 15 July 2004, respectively. IA also shows strong shadow effects, while EA displays prominent delayed mortality responses. Compare to RA in Figure 9.

detected in vegetation that burned when roots or stems remain viable and resprout (McCarron and Knapp 2003, Safford 2004). It is indicative of effects that might appear severe a first, but do not result in sustained loss of individual plants, though aboveground biomass may be temporarily reduced. Compared to IA, site severity is diminished by this response. The opposite is the case for delayed mortality (Ryan et al. 1988, Rebertus et al. 1989, Fowler and Sieg 2004, Agee 2003). It is detected from foliage that appears green and outwardly healthy soon after burning, where heat may minimally scorch or char foliage. Heating, however, effectively damages roots or cambium, and symptoms of necrosis develop over time. Conditions do not appear very severe at first, but actually result in lasting ecological changes as plants die on the site. Compared to IA, site severity is increased by this process. Characteristically not recorded by either RA or IA, delayed survivorship and mortality, nonetheless, are important indicators of the ecological change caused by fire, and integral to defining and quantifying short-term site severity.

Most other first-order effects, such as char, scorch and fuel consumption, are expected to persist until the next growing season, with two exceptions. Areas prone to surface erosion from wind or precipitation may show decrease in ash cover and increase 
of newly exposed mineral soil. Also, canopy foliage that is heat scorched or dies from girdling may drop to litter on the ground over the interval before EA. Since such effects are more or less complimentary to the ecological effects detectable soon after fire, these delayed responses are not expected to significantly alter the remotely sensed magnitude of change detected between IA and EA timeframes.

In Figures 9-10, general improvement in data content and quality is clearly evident from RA until the time of EA, including final representation of the burn perimeter. The influence on severity for this burn is quantified by the dNBR histograms (Figure 11 left). The burn shows slight decrease in the frequency of very high values, due to small amount of regrowth, but fairly large shift in frequency from unburned and low severity values to more mid-range or moderateseverity values. The overall mean dNBR increases from 202 in IA to 270 in EA, indicating a strong influence from delayed mortality between the two samplings. In this case, delayed mortality largely affected conifers burned by relatively low-intensity ground fire.

In contrast, Figure 11 right shows severity dynamics influenced strongly by survivorship between IA and EA. A consistent shift to lower values is evident, and mean dNBR decreases significantly, indicating lower

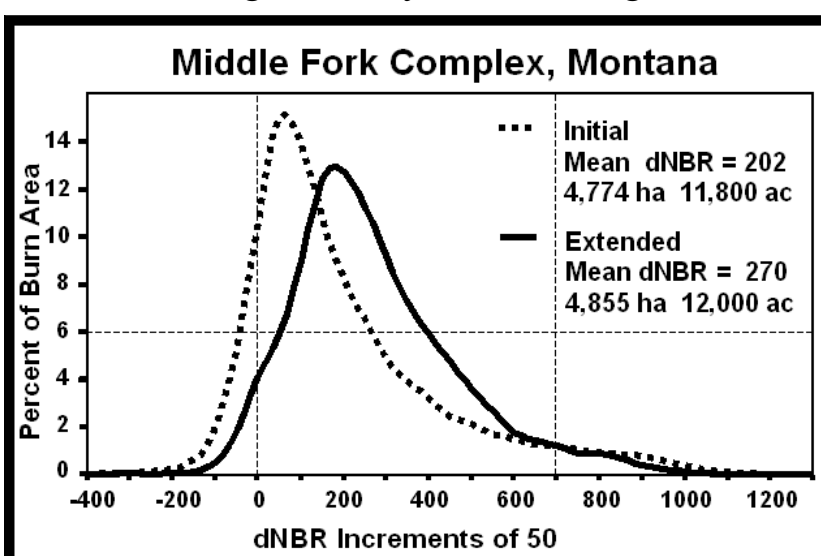

severity overall in EA than initially estimated. The response in any given burn or burn portion, however, depends on the specific fire behavior, pre-fire fuel and vegetation, as well as the weather that prevails during and after fire (McCarron and Knapp 2003, Safford 2004, Slocum et al. 2003). Generally, both responses occur after any given fire (Figure 12). Survivorship and delayed mortality may completely offset one another when considering the whole burn, but rarely is there not some quantifiable effect from one or the other within at least some portions of a burn. Thus, much variation in survivorship and delayed mortality is anticipated between burns, and the dNBR frequency histograms for IA and EA can help identify different burn types based on the balance of ecological responses throughout the whole burn.

\section{SUMMARY}

The relevance of this discussion transcends the particular sensor and remote sensing model applied to mapping burn severity. Indeed, potential data continuity issues facing the Landsat mission may imperil application of Landsat-based dNBR in the near future. Even so, other satellitebased options exist and will remain useful, each creating an intersection between sampling characteristics and ecological fire effects. In so much as detectable fire

Figure 11. Paired IA and EA histograms showing within-burn contrasts in delayed mortality and survivorship detected between the two assessment times on different fires. 
responses relate to resolution, timing, and the quality of radiometric data, the ecological and sampling constraints discussed continue to be germane to remote sensing efforts that define landscape fire severity.

Sensitivities to defining and detecting burn severity are spatial, temporal and radiometric in nature. Spatial factors principally relate to resolution and scale, which determine the aggregation of fire effects (alpha variation) within the minimum sampling unit, or pixel, and control the ability to detect response patches and distribution throughout a burn (beta variation). As the minimum sample unit expands, the distribution and variety of effects become increasingly complex and variable within the unit. The expanding alpha variation extracts progressively more beta variation from the structure of the whole burn and decreases edge distinction. This has implication for the definition of burn severity applied to remote sensing models. Further, it impacts objectives that call for documenting beta variation

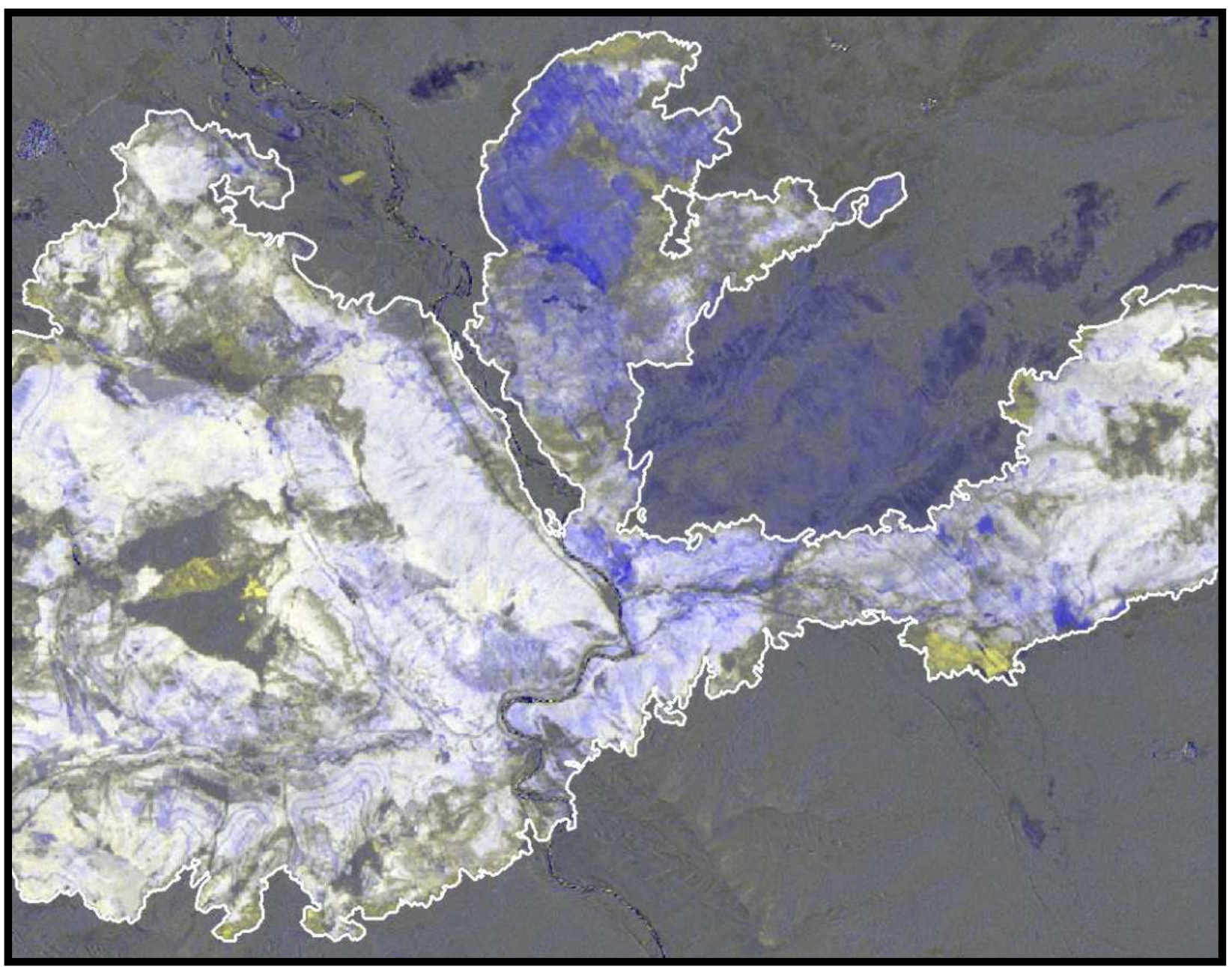

Figure 12. A composite of IA and EA dNBR, displaying IA in blue and EA in red and green bands. Spatially variable responses in survivorship or regrowth (blue) and delayed mortality (yellow) occur throughout the burn. EA severity was much lower in the blue areas and much higher in the yellow areas, compared to IA. Areas with similar dNBR levels between IA and EA appear in neutral gray to white tones, indicating consistent severity detection over the period. Lag times for IA and EA were about 2 weeks and 10 months, respectively. 
across whole burns, but less so when combining broad ranges of response over all burns at small scales.

Temporal sensitivities pertain to time of year and the time since fire when sampling occurs. Seasonal timing can impact radiometric quality of data in terms of transmittance, sun angle, and the potential for enhanced contrast within burn areas. Results typically improve when remote sensing occurs near summer solstice, when illumination is highest, snow effects are minimized, and phenology provides green and productive unburned vegetation that maximally contrasts with fire effects. Remote sensing can degrade during or soon after many fire seasons when incomplete burning, hazy conditions, low sun angles, or plant senescence are more common. In any case, radiometric and seasonal qualities should be selected for optimal discrimination, and multi-temporal datasets should be matched to reliably isolate fire-specific responses from unburned areas. An IA that is delayed to get higher quality data from a particular sensor can ameliorate problems associated with the emergency response RA. An EA, done during the growing season after fire, however, may be the best interval for quality data. Moreover, the lag time enhances detectable qualities of burn severity. Most notable are the first-order effects evident in survivorship and delayed mortality that develop through the growing season after fire. The RA and IA likely miss these ecologically important indicators, resulting in either over- or under- estimating severity. Accordingly, EA may provide more valid and complete representation of severity, with broader potential application over the long term.

Severity and recovery represent complex ecological conditions and processes, with definitions shaped by the data potential collected through sampling. Constraints on fire-response detection and information content point out a need for compatibility between objectives and the sampling approach. Moreover, different spatial and temporal sampling strategies should not be mixed indiscriminately, without understanding the implications. When spatial and temporal sampling factors differ between cases studied, the likelihood of noncomparable results increases. Wrong conclusions may be drawn about differences in severity or fire ecology, as well as about the efficacy of techniques, when studies do not control for these factors across test cases. This is particularly true of studies that analyze multiple burns or test different measures, since observed differences may actually be due to sampling factors unrelated to real fire effects. Thus, fire scientists engaged in quantifying burn severity must recognize that all burn assessments are not equal, and information depends on many spatial and temporal constraints outside of the spectral algorithm alone. Understanding and adapting to such sensitivities will enhance the value of permanent records made more useful for research and long-term management.

\section{ACKNOWLEDGMENTS}

This work was supported in part by the U.S. Geological Survey, National Park Service, and the Joint Fire Sciences Program. Thanks to many individuals in the USGS and NPS for their interest, discussion, assistance and friendship over the years including Nate Benson, Don Ohlen, Zhiliang Zhu, Scott Lange, Brian Sorbel, Stephen Howard, Jan van Wagtendonk, Ralph Root, Randy McKinley, Raymond Kokaly, Richard Menicke, Dennis Divoky, Jerry DeSanto and many others working in fire ecology and monitoring. Also thanks for similar support from Joseph White, Kevin Ryan, Bruce Kilgore, Bob Keane, Duncan Lutes, and Lloyd Queen. 


\section{LITERATURE CITED}

Abrahamson, W.G. 1984. Post-fire recovery of Florida Lake Wales Ridge vegetation. American Journal of Botany 71(1): 9-21.

Agee, J.K. 1993. Fire Ecology of Pacific Northwest Forests. Island Press. 493 pp.

Agee, J.K. 2003. Monitoring postfire tree mortality in mixed-conifer forests of Crater Lake, Oregon, USA. Natural Areas Journal 23(2): 114-120.

Ahern, F.J., T. Erdle, D.A. MacLean, I.D. Kneppeck. 1991. A quantitative relationship between forest growth rates and Thematic Mapper reflectance measurements. International Journal of Remote Sensing 12(3): 387-400.

Beaty, R.M. and A.H. Taylor. 2001. Spatial and temporal variation of fire regimes in a mixed conifer forest landscape, Southern Cascades, California, USA. Journal of Biogeography 28: 955-966.

Bigler, C., D. Kulakowski, T.T. Veblen. 2005. Multiple disturbance interactions and drought influence fire severity in Rocky Mountain subalpine forests. Ecology, 86(11): 3018-3029.

Bobbe, T., M. Finco, P. Maus, A. Orlemann. 2001. Remote Sensing Tools for Burned Area Emergency Rehabilitation (BAER). USDA Forest Service, Remote Sensing Applications Center, RSAC-1-TIP1.

Bond, W.J. and J.J. Midgley. 2003. The evolution ecology of sprouting woody plants. International Journal of Plant Sciences 164(3): S103-S114.

Brewer, C.K., J.C. Winne, R.L. Redmond, D. W. Opitz, M.V. Mangrich. 2005. Classifying and Mapping Wildfire Severity: A Comparison of Methods. Photogrammetric Engineering and Remote Sensing, 71(11): 1311-1320.

Caetano, M.S., L.A.K. Mertes, J.M.C. Pereira. 1994. Using Spectral Mixture Analysis for Fire Severity Mapping. 2nd International Conference on Forest Fire Research, Coimbra, 667677.

Chen, J.M. 1999. Spatial scaling of a remotely sensed surface parameter by contexture. Remote Sensing of Environment 69(1): 30-42.

Chuvieco, E., D. Riaño, F.M. Danson, P. Martin. 2006. Use of a radiative transfer model to simulate the postfire spectral response to burn severity. Journal of Geophysical Research 111(G4): G04S09.

Cibula, W.G., E.F. Zetka, D.L. Rickman. 1992. Response of thematic mapper bands to plant water stress. International Journal of Remote Sensing 13(10): 1869-1880.

Collins, J. B. and C. E. Woodcock. 1994. Change detection using the Gramm-Schmidt transformation applied to mapping forest mortality. Remote Sensing of Environment 50: 267-279.

Cocke A.E., P.Z. Fule, J.E. Crouse. 2005. Comparison of burn severity assessments using Differenced Normalized Burn Ratio and ground data. International Journal of Wildland Fire 14: 189-198.

DeBano, L.F., D.G. Neary, P.F. Folliott. 1998. Fire's Effects on Ecosystems. John Wiley and Sons, New York. 333 pp.

Díaz-Delgado R., F. Lloret, X. Pons, J. Terradas. 2002. Satellite evidence of decreasing resilience in Mediterranean plant communities after recurrent wildfires. Ecology 83(8): 2293-2303.

Epting, J. and D. Verbyla.. 2005. Landscape-level interactions of prefire vegetation, burn severity, and postfire vegetation over a 16-year period in interior Alaska. Canadian Journal of Forest Research 35: 1367-1377. 
Finney, M.A., C.W. McHugh, I.C. Grenfell. 2005. Stand- and landscape-level effects of prescribed burning on two Arizona wildfires. Canadian Journal of Forest Research, 35(7): 1714-1722.

Fowler, J.F. and C.H. Sieg. 2004. Postfire mortality of ponderosa pine and Douglas fir: a review of methods to predict tree death. USDA Forest Service Northern Rocky Mountain Research Station. RMRS-GTR-132. 30 pp.

García-Haro, F.J., M.A. Gilabert, J. Meliá. 2001. Monitoring fire-affected areas using Thematic Mapper data. International Journal of Remote Sensing 22(4): 533-549.

Grau, H.R. and T.T. Veblen. 2000. Rainfall variability, fire and vegetation dynamics in neotropical montane ecosystems in north-western Argentina. Journal of Biogeography 27: 1107-1121.

Gmelin, M. and K. Brewer. 2002. Operational change detection-based fire severity mapping using Landsat TM data. In: J.D. Greer, ed. Proceedings of the ninth Forest Service remote sensing applications conference: Rapid delivery of remote sensing products. San Diego, CA, April 8-12. 2002. American Society of Photogrammetry and Remote Sensing, CD.

Hudak, A.T. and B.H. Brockett. 2004, Mapping fire scars in a southern African savannah using Landsat imagery, International Journal of Remote Sensing 25(16): 3231-3243.

Hudak, A., P. Morgan, C. Stone, P. Robichaud, T. Jain, J. Clark. 2004. The relationship of field burn severity measures to satellite-derived Burned Area Reflectance Classification (BARC) maps. American Society for Photogrammetry and Remote Sensing Annual Conference Proceedings, CD-ROM: 96-104.

Huddle, J. A. and S. G. Pallardy. 1999. Effect of fire on survival and growth of Acer rubrum and Quercus seedlings. Forest Ecology and Management 118: 49-56.

Hunt, E.R. and B.N. Rock. 1989. Detection of changes in leaf water content using near- and middle-infrared reflectances. Remote Sensing of Environment 30: 43-54.

Kauffman, J. B., and R. E. Martin. 1990. Sprouting shrub response to different seasons and fuel consumption levels of prescribed fire in Sierra Nevada mixed conifer ecosystems. Forest Science 36: 748-764.

Key, C. H. and N. C. and Benson. 1999. Measuring and remote sensing of burn severity. In L. F. Neuenschwander and K. C. Ryan (Eds.), Proceedings Joint Fire Science Conference and Workshop, Vol. II, Boise, ID, 15-17 June 1999. University of Idaho and International Association of Wildland Fire. 284 pp.

Key, C.H. and N.C. Benson. 2002. Post-fire burn assessment by remote sensing on National Park Service lands, and Measuring and remote sensing of burn severity. U.S. Geological Survey Wildland Fire Workshop, Los Alamos, NM October 31-November 3, 2000. USGS Open-File Report 02-11: 55-56.

Key, C.H. and N.C. Benson. 2006. Landscape Assessment: Ground measure of severity, the Composite Burn Index, and remote sensing of severity, the Normalized Burn Ratio. In D.C. Lutes, R.E. Keane, J.F. Caratti, C.H. Key, N.C. Benson, S. Sutherland, and L.J. Gangi. 2005. FIREMON: Fire Effects Monitoring and Inventory System. USDA Forest Service, Rocky Mountain Research Station, Ogden, UT. Gen. Tech. Rep. RMRS-GTR-164-CD: LA1-51.

Knipling, E.B. 1970. Physical and physiological basis for the reflectance of visible and nearinfrared radiation from vegetation. Remote Sensing of Environment. 1:155-159.

Kokaly, R., B. Rockwell, S. Haire, T. King. in press. Characterization of post-fire surface cover, soils, and burn severity at the Cerrro Grande fire, New Mexico, using hyperspectral and multispectral remote sensing. Remote Sensing of Environment. 
Lentile, L.B., Z.A. Holden, A.M.S. Smith, M.J. Falkowski, A.T. Hudak, P. Morgan, S.A. Lewis, P.E. Gessler, N.C. Benson. 2006. International Journal of Wildland Fire 15(3): 319345.

Liang, S. 2000. Numerical experiments on the spatial scaling of land surface albedo and leaf area index. Remote Sensing Reviews 19(2): 225-242.

Lieberman, A. and J. Rogan. 2002. Mapping Fire Effects in Southern California Mediterranean Vegetation using IKONOS and Landsat ETM Imagery. Association of Pacific Coast Geographers $65^{\text {th }}$ Annual Meeting, San Bernardino, California, October 2002.

López-García, M.J. and V. Caselles. 1991. Mapping burns and natural reforestation using Thematic Mapper data. Geocarto International 1: 31-37.

Lutes, D.C., R.E. Keane, J.F. Caratti, C.H. Key, N.C. Benson, S. Sutherland, L.J. Gangi. 2006. FIREMON: Fire effects monitoring and inventory system. Gen. Tech. Rep. RMRS-GTR164-CD. Fort Collins, CO: U.S. Department of Agriculture, Forest Service, Rocky Mountain Research Station.

Macarthur, R.H. 1965. Patterns of species diversity. Biological Reviews 40: 510-533.

McCarron, J.K. and Knapp, A.K. 2003. $\mathrm{C}_{3}$ shrub expansion in a $\mathrm{C}_{4}$ grassland: positive post-fire responses in resources and shoot growth. American Journal of Botany 90(10): 1496-1501.

McPherson, G.R., D.D. Wade, C.B. Phillips. 1990. Glossary of Wildland Fire Management Terms Used in the United States. Society of American Foresters, Washington, DC.

Miller, J.D. and A.E. Thode. in press. Quantifying burn severity in a heterogeneous landscape with a relative version of the delta Normalized Burn Ratio (dNBR). Remote Sensing of Environment Ms. No. RSE-D-06-00361R1.

Miller, J.D. and S.R. Yool. 2002. Mapping forest post-fire canopy consumption in several overstory types using multi-temporal Landsat TM and ETM data. Remote Sensing of Environment 82:481-496.

Milne, A. K. 1986. The use of remote sensing in mapping and monitoring vegetational change associated with bushfire events in Eastern Australia. Geocarto International, 1:25-32.

Miura, T., A.R. Huete, H. Yoshioka, B.N. Holben. 2001. An error and sensitivity analysis of atmospheric resistant vegetation indices derived from dark target-based atmospheric correction. Remote Sensing of Environment 78(3): 284-298.

Nelson, K. J. 2005. Evaluating the Effects of Spatial Scale on Remotely Sensed Mapping of Burn Severity: A Comparison of Landsat and MODIS Data. MS thesis. Institute of Atmospheric Sciences, South Dakota School of Mines and Technology. 48 pp.

Orlemann, A., M. Saurer, A. Parsons, and B. Jarvis. 2002. Rapid delivery of satellite imagery for burned area emergency response (BAER). In J.D. Greer, ed. Proceedings of the ninth Forest Service remote sensing applications conference: Rapid delivery of remote sensing products. San Diego, CA, April 8-12, 2002. American Society of Photogrammetry and Remote Sensing, CD.

Patterson, M.W. and S.R. Yool. 1998. Mapping fire-induced vegetation mortality using Landsat Thematic Mapper data: a comparison of linear transformation techniques. Remote Sensing of Environment 65(2): 132-142.

Peterson, S.H. and D.A. Stow. 2003. Using multiple image endmember spectral mixture analysis to study chaparral regrowth in southern California. International Journal of Remote Sensing 24(22): 4481-4504.

Price, J.C. 2003. Comparing MODIS and ETM+ data for regional and global land classification. Remote Sensing of Environment 86(4): 491-499. 
Rebertus, A.J., G.B. Williamson, E.B. Moser. 1989. Longleaf pine pyrogenicity and turkey oak mortality in Florida xeric sandhills. Ecology 70(1): 60-70.

Rogan, J. and J. Franklin. 2001. Mapping wildfire burn severity in southern California forests and shrublands using Enhanced Thematic Mapper imagery. Geocarto International 16(4): 89-99.

Rogan, J. and S.R. Yool. 2001. Mapping fire-induced vegetation depletion in the Peloncillo Mountains, Arizona and New Mexico. International Journal of Remote Sensing 22(16): 3101-3121.

Rogan, J., J. Franklin, D. Roberts. 2002. A comparison of methods for monitoring multitemporal vegetation change using Thematic Mapper imagery, Remote Sensing of Environment 80(1): 143-156.

Romme, W.H. 1980. Fire history terminology: report of the ad hoc committee. In M.A. Stokes and, J.H. Dieterich, eds. Proceedings of the Fire History Workshop, Oct. 20-24, 1980, Tucson, AZ. USDA Forest Service, RMFRES GTR-81: 135-137

Romme, W.H. 1982. Fire and landscape diversity in subalpine forests of Yellowstone National Park. Ecological Monographs 52(2): 199-221.

Roy, D.P., L. Boschetti, S.N. Trigg. 2006. Remote sensing of fire severity: Assessing the performance of the Normalized Burn Ratio. IEEE Geoscience and Remote Sensing Letters 3:112-116.

Ryan, K.C., D.L. Peterson, E.D. Reinhardt. 1988. Modeling long-term fire-caused mortality of Douglas-fir. Forest Science 34(1): 190-199.

Sa, A.C.L., J.M.C. Pereira, M.J.P. Vasconcelos, J.M.N. Silva, N. Ribeiro, A. Awasse. 2003. Assessing the feasibility of sub-pixel burned area mapping in miombo woodlands of northern Mozambique using MODIS imagery, International Journal of Remote Sensing 24 (8): 1783-1796.

Safford, H.D. 2004. Fire effects on plant diversity in serpentine vs. sandstone chaparral. Ecology 85(2): 539-548.

Schimmel, J. and A. Granstrom. 1996. Fire severity and vegetation response in the boreal Swedish forest. Ecology 77(5): 1436-1450.

Slocum, M.G., W.J. Platt, H.C. Cooley. 2003. Effects of differences in prescribed fire regimes on patchiness and intensity of fires in subtropical savannas of Everglades National Park, Florida. Restoration Ecology 11(1): 91-102.

Soja, A.J., Sukhinin, A.I., Cahoon Jr., D.R., Shugart, H.H., Stackhouse Jr., P.W. 2004. AVHRR-derived fire frequency, distribution and area burned in Siberia. International Journal of Remote Sensing 25(10): 1939-1960.

Sorbel, B. and J. Allen. 2005. Space-based burn severity mapping in Alaska's National Parks. Alaska Park Science 4(1): 5-11.

Thode, A.E. 2005. Quantifying the fire regime attributes of severity and spatial complexity using field and imagery data. PhD Dissertation. University of California, Davis, California.

Tucker, C.J. 1980. Remote sensing of leaf water content in the near infrared. Remote Sensing of the Environment 10(1): 23-32.

Turner, M.G., W.W. Hargrove, R.H. Gardner, W.H. Romme. 1994. Effects of fire on landscape heterogeneity in Yellowstone National Park, Wyoming. Journal of Vegetation Science 5(5): 731-742.

USGS EROS. 2006. The National Park Service - U.S. Geological Survey National Burn Severity Mapping Project. U.S. Geological Survey Center for Earth Resources Observation and Science. Retrieved 21 December 2006 from http://burnseverity.cr.usgs.gov/. 
USFS RSAC. 2005. Burned area emergency response (BAER) imagery support. U.S. Forest Service, Remote Sensing Applications Center. Retrieved 9 May 2005 from http:// www.fs.fed.us/eng/rsac/baer/.

Ustin, S.L., M.O. Smith, and J.B. Adams. 1993. Remote sensing of ecological processes: A strategy for developing and testing ecological models using spectral mixture analysis. In J.R. Ehleringer and C.B. Field, eds. Scaling of Physiological Processes: Leaf to Globe. San Diego: Academic Press, 339-357.

van Wagtendonk, J.W., R.R. Root, C.H. Key. 2004. Comparison of AVIRIS and Landsat ETM+ detection capabilities for burn severity. Remote Sensing of Environment 92(3): 397408.

Vogelmann, J.E. and B.N. Rock. 1988. Assessing forest damage in high-elevation coniferous forests in Vermont and New Hampshire using thematic mapper data. Remote Sensing of Environment 24(2): 227-246.

Weir, J.M.H., E.A. Johnson, K. Miyanishi. 2000. Fire frequency and the spatial age mosaic of the mixed-wood boreal forest in western Canada. Ecological Applications 10(4): 11621177.

White, J.D., K.C. Ryan, C.H. Key, and S.W. Running. 1996. Remote sensing of forest fire severity and vegetation recovery. International Journal of Wildland Fire 6(3): 125-136.

Zhu, Z., C. Key, D. Ohlen, N. Benson. 2006. Evaluate Sensitivities of Burn-Severity Mapping Algorithms for Different Ecosystems and Fire Histories in the United States. Final Report to the Joint Fire Sciences Program, JFSP 01-1-4-12. 36 pp. 